\title{
BMJ Open Accessibility and quality of haemodialysis services in an urban setting in South India: a qualitative multiperspective study
}

\author{
Maya Annie Elias (D) , ${ }^{1}$ Wim Van Damme, ${ }^{2}$ Edwin Wouters (D) ${ }^{1}$
}

To cite: Elias MA, Van Damme W, Wouters E. Accessibility and quality of haemodialysis services in an urban setting in South India: a qualitative multiperspective study. BMJ Open 2022;12:e052525. doi:10.1136/ bmjopen-2021-052525

- Prepublication history and additional supplemental material for this paper are available online. To view these files, please visit the journal online (http://dx.doi.org/10.1136/ bmjopen-2021-052525).

Received 23 April 2021 Accepted 19 January 2022

\section{Check for updates}

(c) Author(s) (or their employer(s)) 2022. Re-use permitted under CC BY-NC. No commercial re-use. See rights and permissions. Published by BMJ.

'Department of Sociology, University of Antwerp, Antwerp, Belgium

${ }^{2}$ Public Health, Institute of Tropical Medicine, Antwerp, Belgium

Correspondence to Maya Annie Elias; eliasmaya@gmail.com

\section{ABSTRACT}

Objective To explore the accessibility and quality of existing haemodialysis services in an urban setting. Setting The study was conducted in Bangalore city, India. Participants A total of 28 stakeholders including 2 nephrologists, 7 duty doctors, 13 dialysis technicians and 6 patients on long-term haemodialysis were selected from 20 dialysis centres in Bangalore city.

Design and methods Qualitative study using indepth interviews. A thematic analysis was done using the Availability, Accessibility, Acceptability and Quality Framework of WHO and the Bruce's Quality of Care Framework.

Results The study found several gaps with regard to the access and quality of existing services for patients with end-stage kidney disease (ESKD). The charges for dialysis sessions across settings displayed a wide variance. Patients often started dialysis services in private and later shifted to government and non-governmental organisations-run centres and reduced the number of weekly dialysis sessions due to financial constraints. Most standalone dialysis centres did not have the facilities to manage any emergencies. Most centres did not admit patients with hepatitis or HIV. The quality of care in dialysis centres seemed to be variable and most centres were managed solely by dialysis technicians. There were no psychosocial interventions available to the patients irrespective of the settings. Cost-cutting practices such as employing underqualified technicians, reusing dialysis equipment and using substandard water for dialysis were common.

Conclusion The study highlights the need for more financial and personnel investments in ESKD care in India to ensure optimal care for the growing patient population. The study points towards the need for comprehensive management practices, including diet counselling and psychosocial support. While there are comprehensive guidelines on the establishment and management of dialysis services, more policy attention needs to be on effective implementation of these, to ensure better accessibility and quality of existing services.

\section{INTRODUCTION}

Chronic kidney disease (CKD) has emerged as a major public health challenge worldwide. With a global prevalence of $13.5 \%,{ }^{1}$ it is estimated that approximately 500 million people

\section{Strengths and limitations of this study}

- The study addresses the dearth of knowledge on the accessibility and quality of existing haemodialysis services in a lower middle-income urban setting.

- The study offers a comprehensive perspective on dialysis care by including multiple stakeholders' perspectives.

- Our study demonstrates the applicability of Bruce's Quality of Care Framework to dialysis care.

- Patients undergoing dialysis services from the private sector could not be included in the study sample.

- We included patients undergoing long-term dialysis, who represent a small subset of patients with end-stage kidney disease (ESKD); the findings might therefore not necessarily be generalisable to the whole spectrum of ESKD care.

suffer from CKD, of which $80 \%$ live in low/ middle-income countries (LMICs). ${ }^{2}$ Most LMICs are not equipped to deal with the high burden of CKD; it is often detected at an advanced stage due to the lack of screening programmes and poor awareness. ${ }^{23}$ In India, population-based surveys conducted among adults have reported a high prevalence of CKD. ${ }^{4}$ The Global Burden of Disease Study (2017) reported that there are more than 115 million people with CKD in India. ${ }^{5}$ CKD can be a complication of many diseases: the most commonly reported risk factors for CKD in India are hypertension and diabetes. ${ }^{6-8}$

The progression of CKD is usually slow, ${ }^{9}$ but when the patient reaches the most advanced stage of illness, that is, end-stage kidney disease (ESKD), the kidney functioning is damaged to the extent that the patient needs a renal replacement therapy (RRT), an artificial process used to remove water, electrolytes and waste substances from the blood. Haemodialysis is the most commonly used RRT in India. ${ }^{10}$ The other options are kidney transplant and peritoneal dialysis (PD), but 
these are rarely used in the country. ${ }^{11}{ }^{12}$ Haemodialysis uses an artificial kidney (haemodialyser) to remove waste and extra fluid from the blood. The filtered blood is then returned to the body with the help of a dialysis machine.

Once the patient is advised to undergo haemodialysis, a central venous catheter or an arteriovenous fistula is created as an entry point for haemodialysis. To insert the central venous catheter, a small incision is made in the skin over the selected vein located in the neck, upper chest or groin. The fistula is created between two blood vessels in the patient's arm through a small surgical procedure. In India, most patients undergo emergency haemodialysis, ${ }^{13}$ where a line access using a catheter is created and later patients are advised to switch to the arteriovenous fistula. Haemodialysis sessions usually last 3-5hours. As per the Indian Society of Nephrology guidelines, a patient with ESKD is advised to undergo haemodialysis sessions three times a week. ${ }^{14}$ Along with dialysis, patients need medication and supplements and may require blood transfusions. They need to undergo regular laboratory examinations to check for common infections. Patients with ESKD on dialysis are prone to infections, due to their acquired immune deficiency status, frequent hospital admissions and blood transfusions. ${ }^{15}$ There is a chance of 'machine-to-patient infection' of blood-borne diseases such as hepatitis and HIV during haemodialysis. In India, hepatitis $\mathrm{C}$ virus (HCV) infections among patients who undergo dialysis are reported to be high, and infection is a key cause of mortality among dialysis patients. ${ }^{16}$

Apart from premature mortality, ESKD is also associated with loss of productivity and high financial burden. In India, facilities that offer haemodialysis in the public sector are limited to tertiary care hospitals situated in district headquarters or cities. Due to this, patients have to depend heavily on the private sector for haemodialysis and other support services, which often results in huge out-of-pocket payments for patients and families. ${ }^{17} 18$ Patients with ESKD often require emergency admission to hospital for dialysis, which further adds to their financial burden. The charges for a haemodialysis session in India vary from US $\$ 13$ to US $\$ 40$ (1000-3000 INR (Indian rupees) (US $\$ 1$ is approximately 70 INR)) with additional monthly charges for medicines of about US $\$ 65-\mathrm{US} \$ 70$ (5000 INR) ${ }^{19}$ It has been reported that due to financial constraints, only $10 \%$ of patients with ESKD in India receive any RRT, and of those, $>70 \%$ die within the first 3 months due to inadequate financial resources to continue therapy. ${ }^{20} 21$

While ESKD poses a huge economic burden to patients and families, it also poses significant challenges to health systems. ${ }^{22}{ }^{23}$ Many developed nations spend more than $2 \%-3 \%$ of their annual healthcare budget for the approximately $0.02 \%-0.03 \%$ of patients with ESKD. ${ }^{24}$ Considering the magnitude of ESKD and the financial constraints on patients, the Government of India introduced the Pradhan Mantri National Dialysis Programme in 2016, in which it announced establishing at least one dialysis unit with eight machines in each district to offer free haemodialysis to people living below the poverty line. ${ }^{25}$ However, India still has less than 2000 nephrologists. ${ }^{1026}$ and 4950 dialysis centres (https://www.expresshealthcare.in/features/breakingbarriers-to-dialysis/277182/), of which $80 \%$ operate in the private sector. It is estimated that a centre with 10 haemodialysis machines operating three shifts per day can only cater to 60 patients per week. This is inadequate to meet the existing demand for services.

The research on ESKD in India has largely focused on its prevalence, risk factors and treatment costs. ${ }^{5619}$ There is however a clear knowledge gap regarding the ESKD care process in India: the access to and quality of services offered. This requires in-depth qualitative research complementing the quantitative studies cited. The qualitative studies conducted on ESKD have so far been limited to either singlecentre experiences or solo perspectives from patients or providers. This qualitative study tries to address this research gap by explicitly exploring the access to and quality of ESKD care using multiple stakeholders' perspectives, in an urban setting in South India.

\section{METHODS}

\section{Study design}

With the objective of producing in-depth knowledge on the accessibility and quality of dialysis care in India, a qualitative research design (using thematic analysis) was employed for the study.

\section{Study setting}

The study was conducted in Bangalore, the capital city of Karnataka state in South India. Bangalore city is part of Bangalore urban district, which has an area of 2196 $\mathrm{km}^{2}$ and a population of over 9 million. ${ }^{27}$ The region has 104 primary health centres and 7 general hospitals in the government sector and more than 300 hospitals/nursing homes in the private sector. Bangalore is known for the presence of corporate hospital chains, managed by both national and international players.

\section{Sampling and data collection}

Before the primary data collection, a preliminary mapping of dialysis centres was done by a desktop search, which yielded a result of 88 dialysis centres. From this list, the centres were categorised into three types based on the type of ownership: private, government-run and centres run by charitable institutions or non-governmental organisations (NGOs). To get a good representation of each of these settings, 20 centres were selected purposively for the study, of which 14 were in the private sector, 3 in the government sector and 3 were run by charitable trusts. Basic details of the dialysis centres were captured using a checklist (details captured attached as online supplemental file 1). From these centres, interviews were conducted with a purposively selected consenting sample of patients, dialysis unit technicians, duty doctors and nephrologists to ensure maximal representation of different stakeholders. These interviews were aimed at capturing their perspectives on the dialysis services 


\begin{tabular}{lllrr}
\hline & Type of dialysis facility & & \\
\cline { 2 - 5 } Participant category & Private & Government & NGO & Total \\
\hline Nephrologists & 2 & - & - & 2 \\
Duty doctorst & 1 & 3 & 3 & 7 \\
Dialysis technicians & 8 & 3 & 2 & 3 \\
Dialysis patients & - & 3 & 3 & $\mathbf{2 8}$ \\
Total & & & \\
\hline
\end{tabular}

*The government-run and NGO-run dialysis centres did not have any nephrologists present at the time of visit.

†A medical officer on duty, who is an MBBS graduate. The National Dialysis Programme stipulates the presence of 1 duty doctor for 10 patients.

NGO, non-governmental organisation.

including accessibility and quality-related issues. A semistructured interview schedule based on the WHO's Availability, Accessibility, Acceptability and Quality (AAAQ) Framework (online supplemental file 2 ) $^{28}$ and Bruce's Quality of Care Framework (online supplemental file 3) ${ }^{29}$ was used to capture the different aspects of accessibility and quality of dialysis services by different stakeholders. These interviews were conducted between September and December 2020 by the first author, who is an experienced qualitative researcher. Each interview took 45-60 min (interview topic guide attached as online supplemental file 4). The interviews were conducted in the native spoken language Kannada and were later transcribed to English. Table 1 shows the number of participants interviewed in each category.

\section{Data analysis}

A thematic analysis was done, using NVivo qualitative data management software. ${ }^{30}$ The interview transcripts were imported to NVivo for coding. After the coding, they were categorised into different themes and subsequently these themes were examined and organised into different components of the WHO AAAQ Framework. The quality of care was further categorised as per the Bruce's Quality of Care Framework. This framework identifies six dimensions of quality of care-choice of methods, technical competence, information given to clients, interpersonal relations, mechanisms to ensure follow-up and continuity, and the appropriate constellation of services.

\section{Patient and public involvement}

Patients or the public were not involved in the design, or conduct, or reporting, or dissemination plans of our research.

\section{RESULTS}

\section{Availability of dialysis services}

Most dialysis centres visited were founded in the last 3-6 years. The government-run dialysis centres were attached to general hospitals and run on public-private partnership model, where the facility was located inside government hospital, but the management was by a third-party agency.
While both government and private dialysis centres had 2-10 machines, NGO-run centres had up to 40 dialysis machines. Most of them work three shifts/day and were open 6 days a week (which at maximum capacity equals 18 dialysis treatment sessions per week, supporting a three times per week prescription for up to six patients). The common services included haemodialysis, and supply of medicines and other nutritional supplements. Only three private centres had dietitian services available. Since the government centres were located inside a hospital, patients could get the blood examinations done at the same hospital's laboratories. Six private dialysis centres which were attached to bigger hospitals had laboratory facilities in the premises. The centres, irrespective of the settings, were mostly managed by dialysis technicians and nursing staff. Duty doctors were present in seven private centres, two government centres and one NGO centre. Only two private centres had nephrologists at the time of visit. Other centres reported that they have a visiting nephrologist, who is 'on call'.

\section{Accessibility of dialysis services}

Physical accessibility

All dialysis centres catered to patients coming from a distance of $20-40 \mathrm{~km}$. In the centres run by charitable institutions, a few patients were coming from the nearby districts travelling 3-4hours for each dialysis session. All centres in the government and NGO sector were run at full capacity. Technicians across settings reported of increase in patient numbers over the years. Technicians from four dialysis centres in private sector and two centres in NGO sector reported starting additional shifts in the last 2 years. A senior technician from a private centre observed:

In 1999, we had two dialysis machines and we used to do two shifts, now we have to do daily 4 emergency dialysis, apart from managing the regular patients. Patient numbers have increased, it has become common like a fever. Now we have about 8 machines, and all the machines are occupied, except for the latenight session. (Technician_private) 
Stand-alone centres do three shifts usually while centres that are part of larger chains such as [centre name], have started night shifts too. The Government-run centres usually do not have enough manpower and other supplies to run extra shifts. (Nephrologist_private)

While the private centres had both short-term and long-term patients, the government-run and NGO-run centres reported to have a fixed set of clientele, with most patients coming from the inception of the centre or for a period of 3-4 years. Only when an existing patient died or moved to another centre, a new admission took place. While the private centres received occasional enquiries of new patients, all government-run and NGO-run centres visited had more than 10 patients waiting to be enrolled, and the waiting period was approximately 3-6 months. When there was a vacancy, patients coming with staff or local political leaders' recommendations were given priority for admission.

\section{Non-discrimination (accessibility for all patients)}

Only three centres provided dialysis for patients with hepatitis B, hepatitis C or HIV, commonly referred to by the staff as 'positive patients'. All the centres, irrespective of the setting, insisted on a blood test for these three conditions as a prerequisite for admission and if the result was positive, most centres denied admission. According to the staff, it is mainly due to the lack of infrastructure, human resources and cost concerns. The centres catering to patients with these conditions kept one to two machines exclusively for them and allotted a technician exclusive to this section. For such patients, dialyser and other accessories were for single use. For small centres, this is not cost-effective, so they did not admit any positive patients.

There should be a separate setup for Hepatitis C, B and HIV positive patients. We cannot have the same machines. We have done a separate setup for this, but right now we are not doing it because for positive cases, the cost is double. (Duty doctor_NGO)

We don't admit seropositive [hepatitis B and C, HIV] cases here. Not many positive cases come here. We want to make optimum use of the machines, so we don't take them.(Nephrologist_private)

The standalone dialysis centres did not have the capacity to take care of emergencies, so they did not admit patients with comorbid heart or lung-related conditions or other complications. Patients who needed emergency care had to depend on higher-level centres.

\section{Economical accessibility (affordability)}

All the patients interviewed were from lower to lowermiddle socioeconomic status and were availing dialysis services from government-run and NGO-run centres. All of them were long-term dialysis patients undergoing dialysis for the last 3-10 years and reported having started their dialysis sessions from private centres and later shifting to either NGO/government-run centres due to financial constraints. Only one patient was working as an auto driver, all others depended on family members for financial support. Three patients reported that they were employed before they were diagnosed with ESKD, and they had to leave their jobs due to the illness symptoms and repeated hospitalisations. None of them had any insurance coverage.

In private centres visited, the out-of-pocket expenditure per dialysis session varied between US $\$ 11.4$ and US $\$ 42.8$ (INR to US\$ calculated at the conversion rate of 70) (800 and 3000 INR). Government-run and NGO-run centres offered subsidised care; the average cost borne by patients per dialysis session was US $\$ 5.7-U S \$ 7.1$ (400500 INR) excluding the charges for blood investigations and medications. The technicians reported that approximately $30 \%-40 \%$ of their patients had severe anaemia and required additional injections or blood transfusion. They reported that on average, monthly blood investigations would cost US\$50-US\$71.4 (3500-5000 INR) in private centres, and US\$14.2-US\$21.4 (1000-1500 INR) in charitable centres. Patients with other common comorbid conditions would pay about US\$500 (35000 INR) in private centres and about US $\$ 142.8-$ US $\$ 171.4$ (10 000-12 000 INR) in government-run and NGO-run centres per month. Due to financial constraints, patients often skipped dialysis sessions or shifted from private dialysis centres to either government or NGO facilities. In the long run, patients often reduced the weekly dialysis sessions and frequency of blood examinations.

I am not able to earn for the last ten years, I had to use all my savings for the treatment, I have spent about 18 Lakhs [US\$25 000] so far. I have to pay rent. My wife was not working. After I became a patient, she started going to nearby houses as a domestic help. I started coming here now because I don't have money to go to private. (Patient_government)

We try to do 3 dialyses [per week] for everyone. But if they cannot bear the cost, then they do 2 dialyses. They do this to save 300-400 rupees a week, but if they get into any complication [because they skipped dialysis], then they will end up spending 30 to 40 thousand rupees to manage that. (Duty doctor_private)

\section{Quality of care}

The key findings related to quality of dialysis services are organised below, using the six dimensions stipulated in the Bruce's Quality of Care Framework.

\section{Choice of methods}

Haemodialysis was the only RRT provided, except for one private centre which offered kidney transplants. None of the visited centres provided PD. The technicians shared that though they have learnt about PD and its advantages, they never practised it. According to them, in the Indian context, it is difficult for patients to opt for PD because the surroundings need to be kept sterile and clean and 
most patients do not have enough resources for that. None of the interviewed patients was given PD as a treatment option and they were not aware of the PD process. None of them had registered for renal transplant.

I have spoken to doctors abroad. There they prefer Peritoneal Dialysis. Here we don't do it because patients can't afford to have a separate room for it, also the fluid they use is very expensive. It could be because only a few people are using it. (Technician_NGO)

PD has to be done $24 / 7$, and here it is not very practical. Also you need the presence of someone to assist. Patient housing and other conditions are not very suitable for PD in our setting. So, PD is slowly going out of practice here. (Nephrologist, private)

\section{Information given to clients}

Patients reported that they did not have any prior knowledge of ESKD, its symptoms or management before they were diagnosed. All of them were caught unaware of kidney failure as a complication of diabetes or hypertension and were subsequently advised to undergo haemodialysis. Nephrologists and technicians reported that most patients came with kidney failure because of undetected hypertension or diabetes. Patients reported that they learnt about the complications of dialysis, diet and weight management over the years, and tried to manage complications at home to the extent possible.

I had BP [Hypertension]. I was not taking medicine. I neglected. I didn't know it will lead to this type of problem [kidney disease]. (Patient_NGO)

Most patients will present with symptoms of renal failure, and when we do the examinations, many will have uncontrolled diabetes or hypertension. When we ask the patients why they did not take medicines, they say we did not know. (Nephrologist, private)

\section{Interpersonal relations}

All dialysis centres provided dialysis in open wards, with beds next to each other. Since most patients had fixed days and time for dialysis, they saw and interacted with the same set of fellow patients. Patients shared their experiences and learnt from their peers about managing the symptoms. A duty doctor in a government centre observed that having open wards helped in reducing patient anxiety regarding the dialysis process.

I think open wards are good. Even screens between patients are not necessary. If there is a screen and we are attending a patient [with complication], other patients think we are doing something to the patient and start worrying. If it is open, then they can see openly what we are doing and what we are saying. They will know there is nothing serious. (Duty doctor_NGO)

A nephrologist observed that in government-run and NGO-run centres, patients had more opportunities to interact with other patients. In private centres, most patients would arrive at their fixed time for the dialysis and their interactions are usually limited to the staff and at most the patients who occupy the next bed.

\section{Mechanisms to ensure follow-up and continuity}

Technicians and duty doctors from the NGO-run centres reported that patients regularly attended their scheduled dialysis sessions since it was free or subsidised. Patients were advised not to travel for more than 2 days. When patients had to travel to far-off places or for longer duration, either they must skip a scheduled dialysis or they must enrol in a local dialysis centre. Staff shared that this is a common reason for infections.

Some patients travel to their hometown or relatives' houses for festivals or family functions. If they go for more than two days, they have to get the dialysis done and will go to some local place and get it done. Once they come back and we do the blood test, we find that they have become positive for Hepatitis B or C. (Techinician_private)

All centres maintained patient records. A few centres had detailed case notes including previous treatment details, lab reports and other clinical parameters, while others kept only patient contact details along with the blood pressure readings and weight on the day of dialysis.

\section{Appropriate constellation of services}

The dialysis centres in the private sector had better infrastructure, separate beds and screens or curtains between the beds. Government and NGO centres provided the services in open wards, with beds next to each other. There was no separation between male and female wards in most of the centres. From the dialysis centres visited, three centres in the private sector had a dietitian who provided diet counselling to the newly admitted patients. Patients undergoing dialysis under government centres, where the medicines are supplied free of cost, often faced a shortage of required medicines and supplements. Due to this, they had to spend money on purchasing medicines from private pharmacies.

Because medicines were not available, many times I have gone to other places to get it. Even last month I had gone to another centre. We complained to the Medical Officer last month and after that, there is no problem. (Patient_government)

While it was noted that patients often felt helpless and hopeless thinking about the treatment expenses and the prognosis of their illness, none of the visited dialysis centres had any counsellors or social workers offering counselling or any other psychosocial support to patients.

All your money will all be spent [for the treatment]. If you go inside the ICU once, you will need a minimum of 50000 rupees. It has been very difficult for me; I have even thought of committing suicide. What else can be done? (Patient_NGO) 
I have not seen a counsellor in any dialysis centre. In India, we don't have the concept of a counsellor. Only the doctors talk to the patients. There is an issue of time constraint. We may not have enough time to talk to everyone. (Nephrologist_private)

\section{Technical competence}

All the visited centres, irrespective of the sectors, were mainly managed by dialysis technicians. Seven centres had duty doctors, only two centres had full-time nephrologists. In all visited centres, one or two technicians managed the centres with 7-10 patients in a single shift. They reported that there are 6 months- 1 year dialysis technician courses available and such courses do not equip the technicians to notice complications during dialysis.

In many centres there are no nephrologists, and there are unqualified technicians. They may not even know how to read and write properly, but they will be doing dialysis. They just know how to switch the machine on and off, nothing else. (Nephrologist_private)

Private dialysis centres have less qualified technicians to cut costs. They may not practice safety precautions while handling of the dialyzer and other equipments which would lead to infections and other complications. Patients won't know what is happening. (Technician_government)

Due to human resource crunch, the same technicians handle patients with and without infections such as hepatitis and HIV. This, coupled with their lack of adequate training, puts patients at risk of infections. Other costcutting practices reported were the use of lower quality water purifiers, and other equipment including dialysers and tubes. These practices led to patients getting infections and having other complications during dialysis. All centres used the dialyser for 10 dialysis sessions for a patient and all three centres in government reused the tubes as well. The technicians shared that if the machine parts were not cleaned with strict safety precautions, 'machine-to-patient infections' could happen. Technicians and duty doctors reported that they commonly saw infections such as HCV and hepatitis B virus (HBV) among patients. Staff from a few dialysis centres mentioned that they did not admit patients referred from certain centres due to the fear of transmission.

People with Kidney Disease are prone to get Hepatitis $\mathrm{C}$ and many hospitals are spreading it like anything. Some hospitals, I can name them, they are harbouring this and spreading. Patients coming from certain hospitals, we know that they will be positive, we know that their quality of treatment is poor. (Duty doctor_NGO)

The water quality is very important; centres are supposed to have monthly water test to make sure the bacteria and toxic elements are controlled. But it costs about $4000-5000$ rupees to do it, so most centres don't do it monthly. (Nephrologist_private)

\section{DISCUSSION}

This study throws light on the landscape of dialysis services offered in an urban setting in South India and poses a few important questions on the accessibility and quality of existing services. While it appears that the availability of haemodialysis services may not be a serious issue, economic access is a major challenge. Although dialysis services are predominantly offered by the private sector, the wide variability in charges for dialysis and support services renders them inaccessible for large groups of patients. Though the centres in the government and NGO settings charge comparatively less per dialysis session, patients from poorer families still do not have sufficient resources to afford these. Also, such centres are too few in numbers to be able to cater to the rising demand for dialysis services. Our findings showed that due to financial constraints, patients are often forced to skip dialysis sessions. Similar findings were reported earlier by $\mathrm{Jha}^{31}$ and Karopadi et al. ${ }^{32}$ Another study conducted by Kaur et al found the prevalence of catastrophic health expenditure to be as high as $51 \%$ among patients undergoing haemodialysis three times per week. ${ }^{33}$

In India, diabetes and hypertension are the key causative factors for CKD and these conditions make patients prone to complications during dialysis. Earlier studies have reported that hypotension, nausea and vomiting are commonly reported during dialysis. Our study too showed similar findings. ${ }^{34}$ While infections, especially $\mathrm{HCV}$ and $\mathrm{HBV}$, are commonly reported in the population with CKD due to frequent dialysis and blood transfusions, the number of centres catering to patients with these conditions is very limited. Patients with any comorbid conditions and other complications need to depend on higher centres with emergency facilities, which are too few, especially in the public sector. Private hospitals can cater to only a subsection of patients with ESKD, who can afford their services So, patients end up shuttling between centres in different settings depending on their illness status and paying capacity.

The study findings raise important questions regarding the overall quality of dialysis services across settings. The quality of the dialyser and water used for dialysis is an important predictor for better patient outcomes. ${ }^{35}$ Our study showed that water purifiers are available at varying costs and currently there are no mechanisms to ensure the water quality. Though national guidelines and guidelines issued by the Indian Society of Nephrologists recommend that nephrologists must be part of regular staff in the haemodialysis centres, the centres are managed solely by dialysis technicians and from our respondents' accounts, it appears that the quality of their training is variable. If technicians are capable of identifying the early warning signs, many complications could be averted, including problems with fistula. $^{36}$

Though the benefits of Peritoneal Dialysis (PD) is well documented ${ }^{37}$ our findings show that it is still not accessible to patients with CKD. Acknowledging this, the Government of India published a set of guidelines 
for states for starting PD facilities as part of the Pradhan Mantri National Dialysis Programme. ${ }^{38}$ It provides the necessary guidance for states to set up PD centres and serves as a best practice document for providers of $\mathrm{PD}$, ensuring delivery of high-quality, cost-effective Continuous Ambulatory Peritoneal Dialysis services. While it is a welcome move, states will have to implement it in an effective and timely manner.

CKD is known to be associated with various psychological issues such as depression, anxiety and poor quality of life. A multicentre study conducted in India found that depression was common among haemodialysis patients, and long-term dialysis and poverty status had a significant relationship with depression. ${ }^{39}$ Another study conducted among patients with CKD from Karnataka reported depression to be more common in patients on dialysis compared with other modalities of treatment. ${ }^{40}$ While supportive interventions have been found to be effective among patients with $\mathrm{CKD},{ }^{41}$ our findings indicate that existing services do not cater to the psychosocial needs of the patients. Having the services of a trained counsellor or a social worker available in these centres would give the patients an opportunity to discuss their psychosocial problems, which could potentially help in reducing their emotional discomfort during the dialysis process and improve overall treatment outcome. Earlier studies have reported a positive effect of counselling on patients with CKD. $^{42}$

\section{Limitations of the study}

While the study provides a snapshot of the dialysis services provided in an urban setting in India, it is subject to certain limitations. The study took place in a selection of dialysis care facilities in an urban setting in India and the results might therefore not necessarily be generalisable to other settings. Due to the difficulty in obtaining necessary approvals from the authorities, patients undergoing dialysis services from the private sector could not be included in the study sample. The study respondents were undergoing dialysis for longer term, and we acknowledge that they represent a small subset of patients with CKD and the findings apply to this subset of patients and not necessarily the entire spectrum of CKD.

\section{Implications of the study and future directions}

By including multiple stakeholders, our study offers a comprehensive perspective on CKD care in a lower middle-income urban setting. It also demonstrates the applicability of Bruce's Quality of Care Framework to ESKD care. The study highlights the need for more financial and personnel investments in ESKD care in India to ensure optimal care for the growing patient population. The study points towards the need for comprehensive management practices, including diet counselling and psychosocial support. While there are comprehensive guidelines on the establishment and management of dialysis services, more policy attention needs to be on effective implementation of these, to ensure better access and quality of existing services. With the increasing burden of CKD in India, more in-depth studies are needed, exploring patient experiences at different stages of their illness, which would help in designing appropriate interventions at each stage of CKD.

Acknowledgements We thank Dr Yashwanth Kumar KY, Assistant Professor, Department of Nephrology, Vydehi Institute of Medical Sciences and Research Centre, Bangalore for his analytical inputs. We thank Professor Arima Mishra, Azim Premji University, Bangalore for her guidance and support. We acknowledge Dr Thriveni S Beerenahalli for her help and support for the study.

Contributors MAE conceptualised the study, in consultation with WVD and EW. MAE collected the data, conducted the first level of analysis and prepared the first draft of the manuscript. WVD contributed to the study design, data analysis and writing the manuscript. EW contributed to data analysis and writing the manuscript. All three authors participated in data analysis discussions, revision of the manuscript and concurred on the final draft of the manuscript. MAE is responsible for the overall content as guarantor and accepts full responsibility for the conduct of the study, collected data and the the decision to publish.

Funding The authors have not declared a specific grant for this research from any funding agency in the public, commercial or not-for-profit sectors.

Competing interests None declared.

Patient consent for publication Not required.

Ethics approval The study protocol was approved by the Ethics Committee for the Social Sciences and Humanities EA SHW- of the University of Antwerp, Belgium (ref no: SHW_18_82) and permission was taken from the centre authorities before the interviews. Informed consent was taken from the participants. Confidentiality was maintained, all identifying details were removed from the interview transcripts. Authors adhered to the Standards for Reporting Qualitative Research (SRQR), throughout the course of the study.

Provenance and peer review Not commissioned; externally peer reviewed.

Data availability statement Data are available upon reasonable request.

Supplemental material This content has been supplied by the author(s). It has not been vetted by BMJ Publishing Group Limited (BMJ) and may not have been peer-reviewed. Any opinions or recommendations discussed are solely those of the author(s) and are not endorsed by BMJ. BMJ disclaims all liability and responsibility arising from any reliance placed on the content. Where the content includes any translated material, BMJ does not warrant the accuracy and reliability of the translations (including but not limited to local regulations, clinical guidelines, terminology, drug names and drug dosages), and is not responsible for any error and/or omissions arising from translation and adaptation or otherwise.

Open access This is an open access article distributed in accordance with the Creative Commons Attribution Non Commercial (CC BY-NC 4.0) license, which permits others to distribute, remix, adapt, build upon this work non-commercially, and license their derivative works on different terms, provided the original work is properly cited, appropriate credit is given, any changes made indicated, and the use is non-commercial. See: http://creativecommons.org/licenses/by-nc/4.0/.

\section{ORCID iDs}

Maya Annie Elias http://orcid.org/0000-0003-3855-0801

Edwin Wouters http://orcid.org/0000-0003-2268-3829

\section{REFERENCES}

1 Hill NR, Fatoba ST, Oke JL, et al. Global Prevalence of Chronic Kidney Disease - A Systematic Review and Meta-Analysis. PLoS One 2016;11:e0158765.

2 Stanifer JW, Muiru A, Jafar TH, et al. Chronic kidney disease in low- and middle-income countries. Nephrol Dial Transplant 2016;31:868-74.

3 Jha V, Garcia-Garcia G, Iseki K, et al. Chronic kidney disease: global dimension and perspectives. The Lancet 2013;382:260-72.

4 Anupama YJ, Uma G. Prevalence of chronic kidney disease among adults in a rural community in South India: results from the kidney disease screening (kids) project. Indian J Nephrol 2014;24:214.

5 GBD Chronic Kidney Disease Collaboration. Global, regional, and national burden of chronic kidney disease, 1990-2017: a systematic 
analysis for the global burden of disease study 2017. Lancet 2020;395:709-33.

6 Singh AK, Farag YM, Mittal B V. Epidemiology and risk factors of chronic kidney disease in India-results from the SEEK (Screening and Early Evaluation of Kidney Disease) study [Internet], 2013. Available: http://www.biomedcentral.com/1471-2369/14/114

7 Dash SC, Agarwal SK. Incidence of chronic kidney disease in India. Nephrol Dial Transplant 2006;21:232-3.

8 Rajapurkar MM, John GT, Kirpalani AL, et al. What do we know about chronic kidney disease in India: first report of the Indian CKD registry. BMC Nephrol 2012;13:10.

9 Metcalfe W. How does early chronic kidney disease progress? [Internet]. In: Nephrology dialysis transplantation. . Institute for Quality and Efficiency in Health Care (IQWiG), 2007: Vol. 22. 26-30. https://www.ncbi.nlm.nih.gov/books/NBK492987/

10 Varughese S, Abraham G. Chronic kidney disease in India: a clarion call for change. Clin J Am Soc Nephrol 2018;13:802-4.

11 Kute VB, PRPS S, Vanikar A V. Increasing access to renal transplantation in India through our single-center kidney paired donation program: A model for the developing world to prevent commercial transplantation [Internet. Transplant International Blackwell Publishing Ltd, 2014: 1015-21. http://doi.wiley.com/10.1111/tri.12373

12 Jha V, Ur-Rashid H, Agarwal SK, et al. The state of nephrology in South Asia. Kidney Int 2019;95:31-7 http://www.kidney-international. org/article/S0085253818306045/fulltext

13 Hemachandar R. Practice pattern of hemodialysis among endstage renal disease patients in rural South India: a single-center experience. Saudi J Kidney Dis Transp/ 2017;28:1150-6.

14 Jha V, Kohli HS, Agarwal SK. Indian Society of nephrology guidelines for hemodialysis units. Indian J Nephrol 2012;22.

15 Narayanan M. The many faces of infection in CKD: evolving paradigms, insights, and novel therapies. Adv Chronic Kidney Dis 2019;26:5-7.

16 Johnson DW, Dent $\mathrm{H}$, Yao Q et al. Frequencies of hepatitis $\mathrm{B}$ and $C$ infections among haemodialysis and peritoneal dialysis patients in Asia-Pacific countries: analysis of registry data. Nephrol Dial Transplant 2009;24:1598-603.

17 Mushi L, Marschall P, Fleßa S. The cost of dialysis in low and middleincome countries : a systematic review, 2015: 1-10.

18 Jeloka TK, Upase S, Chitikeshi S. Monthly cost of three exchanges a day peritoneal dialysis is same as of thrice a week hemodialysis in self-paying Indian patients. Indian J Nephrol 2012;22:39.

19 Agarwal SK. Chronic kidney disease and its prevention in India. Kidney Int 2005;68:S41-5.

20 Liyanage T, Ninomiya T, Jha V, et al. Worldwide access to treatment for end-stage kidney disease: a systematic review. Lancet 2015;385:1975-82.

21 Parameswaran S, Geda SB, Rathi M, et al. Referral pattern of patients with end-stage renal disease at a public sector hospital and its impact on outcome. Natl Med J India 2011:24:208-13.

22 Schieppati A, Remuzzi G. Chronic renal diseases as a public health problem: epidemiology, social, and economic implications. Kidney Int 2005;68:S7-10.

23 World Health Organization. Who operational package for assessing, monitoring and evaluating country pharmaceutical situations: guide for coordinators and data collectors. Geneva: World Health Organization, 2007.

24 Couser WG, Remuzzi G, Mendis S, et al. The contribution of chronic kidney disease to the global burden of major noncommunicable diseases. Kidney Int 2011;80:1258-70.

25 Jha V. Universal health coverage for dialysis in India - First steps towards change. Lancet Kidney Campaign [Internet], 2016. Available: https://www.thelancet.com/campaigns/kidney/updates/ universal-health-coverage-for-dialysis-in-india [Accessed $03 \mathrm{Jul}$ 2020].

26 Sharif MU, Elsayed ME, Stack AG. The global nephrology workforce: emerging threats and potential solutions! Clin Kidney J 2016;9:11-22.

27 Govt of India. Census of India [Internet], 2011. Available: http:// censusindia.gov.in/DigitalLibrary/Books.aspx [Accessed 03 Mar 2019].

28 United Nations. UN General Assemby: Political Declaration of the High-level Meeting of the General Assembly on the Prevention and Control of Non-communicable Diseases [Internet], 2012. Available: http://www.who.int/nmh/events/un_ncd_summit2011/political_ declaration_en.pdf

29 Bruce J. Fundamental elements of the quality of care: a simple framework. Stud Fam Plann 1990;21:61-91.

30 QSR International Pty Ltd. NVivo qualitative data analysis software, 2012.

31 Jha V. Current status of end-stage renal disease care in India and Pakistan. Kidney Int Suppl 2013;3:157-60.

32 Karopadi AN, Mason G, Rettore E, et al. Cost of peritoneal dialysis and haemodialysis across the world. Nephrology Dialysis Transplantation 2013;28:2553-69.

33 Kaur G, Prinja S, Ramachandran R, et al. Cost of hemodialysis in a public sector tertiary hospital of India. Clin Kidney J 2018;11:726-33.

34 Prabhakar, Singh RG, Singh S, et al. Spectrum of intradialytic complications during hemodialysis and its management: a singlecenter experience. Saudi J Kidney Dis Transp/ 2015;26:168-72.

35 Coulliette AD, Arduino MJ. Hemodialysis and water quality. Semin Dial 2013;26:427-38.

36 Rai K. Salvaging dialysis fistula and grafts. Indian J Vasc Endovasc Surg 2017;4:36-7.

37 Makkar V, Kumar M, Mahajan R, et al. Comparison of outcomes and quality of life between hemodialysis and peritoneal dialysis patients in Indian ESRD population. J Clin Diagn Res 2015;9:28-31.

38 Pradhan Mantri national dialysis programme guidelines for establishing peritoneal dialysis services 2019.

39 Vettath RE, Reddy YNV, Reddy YNV, et al. A multicenter crosssectional study of mental and physical health depression in MHD patients. Indian J Nephrol 2012;22:251-6.

40 Khan WA, Ali SK, Prasad S, et al. A comparative study of psychosocial determinants and mental well-being in chronic kidney disease patients: a closer look. Ind Psychiatry J . 2019;28:63.

41 Hedayati SS, Yalamanchili V, Finkelstein FO. A practical approach to the treatment of depression in patients with chronic kidney disease and end-stage renal disease. Kidney Int 2012;81:247-55.

42 Abraham S, Ramachandran A. Estimation of quality of life in haemodialysis patients. Indian J Pharm Sci 2012;74:583-7. 